\title{
METODOLOGICAL ISSUES IN MEASURING THE DETECTION OF EMOTIONAL DISORDERS BY PRIMARY CARE PHYSICIANS
}

\author{
A REVIEW OF THE LITERATURE:
}

Eduardo Iacoponi*

\begin{abstract}
IACOPONI, E. Metodological issues in measuring the detection of emotional disorders by primary care physicians. A review of the literature. Rev. Saúde públ., S. Paulo, 22:46-56, 1988.
\end{abstract}

ABSTRACT: A series of studies in the field of Epidemiological Psychiatry have been performed over the last two decades, and these have focused on the ability of primary care physicians to detect emotional disorders in the patients that attend their practices. The scientific methodology utilized in these studies is the subject of this review, which contains a discussion concerning: a) interviewer awareness bias; b) accuracy of the instruments and c) medical and psychological concepts involved in defining minor emotiona! disorders. Suggestions for change in the methodology are made in each of the sections of the review.

UNITERMS: Epidemiologic methods. Mental disorders, diagnosis. Primary health care. Mass screening, methods.

"I presented her with the cube and the sphere which she had so often had in her hand before, and asked her what they were. She could neither name them correctly, nor in any way describe their form aright: indeed I remained very doubtful whether she hat actually recognized them even as distinct from one another." (From "Space and Sigh". Mar ion Senden 42,1936$)$.

\section{INTRODUCTION}

The subject of this review is the methodology used in studies designed to measure the ability of primary care physicians to detect mental illness in their practices. The main aims of these epidemiological studies are the provision of guidance for the logical planning of health services, since their immediate usage is the training and selecting of medical manpower appropriate for primary health care settings. This aim stems from another basic aim of Epidemiology (MacMahon and $\mathrm{Pugh}^{31}, 1970$ ), the understanding of the factors that influence the course of a disease once established. For, it is assumed, early detection and consequent management interfere in the natural history of many phychiatric disorders

Interest in the epidemiology of psychiatric disorders in Primary Care has increased in the last three decades, as a consequence of the scientific and social needs of Psychiatry to observe major mental disorders in settings other than the institutions for the mentally ill (Shepherd and Coopert3, 1964). As the bulk of disorders then found by general practitioners and in the community differed sharply from those found in psychiatric hospitals, new methods of identification were developed for neuroses, anxiety and depressive states, forming the group that was later to be called "minor psychiatric disorders". At the same time, Primary Health Care was being universally indicated as a tentative way out of the increasing expenditures on health, a setting in which patients would have: first contact with the health system in places easily accessible to local communities; longterm advice on questions like when, where and how much to use technological facilities; comprehensive and more humanistic care under not only the doctor's responsibility, but also under that of a team of other health professionals $\left(\mathrm{WHO}^{51}, 1978\right)$.

These two trends described above led to the investigations, mainly conducted in England and the United States, that demons-

* Supported by "Conselho Nacional de Desenvolvimento Científico e Tecnológico" (CNPq) grant. Process n. 2875/85-CL.

** Institute of Psychiatry. General Practice Research Unit. De Crespigny Park. Denmark Hill. London SE5 SAF - England. 
trated the impact of psychiatric disorders in primary care settings, and were accompanied by many other studies (Hankin and Oktay ${ }^{17}$, 1979; Wilkinson $\left.{ }^{48}, 1985\right)$. It was shown that a large proportion of patients attending primary care clinics presented some sort of psychiatric disorder (Shepherd et $\mathrm{al}^{44}, 1966$ ), in rates that depended upon the identification method used in the study; it was also demonstrated that, considering the distribution of all psychiatric patients according to the setting where they were receiving medical care, the majority of them were to be found not in the psychiatric sector, but in the primary care setting (Regier et $\mathrm{al}^{38}, 1978$ ).

In 1972, one of the most prolific authors on the subject, together with one of the pioneers (Goldberg and Kessel ${ }^{13}$, 1975), wrote:

"...studies on the prevalence, distribution, and types of psychiatric illness in general practice have been executed in profusion. The 'How many' and 'What sort' questions have largely been answered and we are now at a time when it is appropriate to embark on a different series of studies. Attention must increasingly be focused upon aetiological inquiries, upon outcome studies, upon how the doctor does his work and upon treatments and their effects."

The ability of the primary care doctor to detect mental illness has recently appeared as an important theme for study. After all, needless to say, the health system in its primary care sector places doctors as the professionals performing the main role in the ultimate decisions concerning the patients' health problems. Where management of minor psychiatric disorders is involved - the disorders most prevalent in the practices of the primary care physicians - proper detection is a fundamental step (WHO ${ }^{50}, 1973$ ). And adequate measuring of this detection becomes the task of the epidemiologist.

The methodology used to measure the doctor's recognition of psychiatric disorders tends to follow similar designs, is still quite recent and has not yet been submitted to a critical review; which it deserves, because, on this basis, many conclusions have been drawn and suggestions for policy change in medical education and public health are already being made.

\section{THE MEASUREMENT OF DETECTION}

In order to facilitate the examination of some of the issues of epidemiologic research on the measurement of doctors' ability to detect mental disorders, they will be discussed under three headings:

\section{A) Doctors' Awareness \\ B) Accuracy of Instruments \\ C) Conceptual Clash}

Before this, a research design typically employed in these studies will be presented. It is based mostly on the more recent investigations*, which are conducted approximately as follows:

- these studies are usually carried out by psychiatrists working in the field of epidemiology; sociologists, social workers and nonpsychiatrist physicians are sometimes also responsible for making the contacts with the doctors being studied, and they may or may not be present at the places where the data are being collected.

- doctors working in single or group practices are asked to participate in a study; since only those who agree to collaborate actually take part in the investigation, the selection is not randomized; little is known of the differences between those doctors who participate and those who do not.

- the instruments most commonly utilised in these studies are relatively simple ones, where the presence and intensity of psychiatric disturbance observed by the doctors is scored in small scales; as for convenience these instruments will be called here "Doctor's Scales".

- as a rule, the selected doctors are not fully informed as to the objectives of the study; in the sheet containing the Doctor's Scale, four to five lines say that the investigation intends to study psychiatric disorders at the Primary Care level; no definitions of terms like "psychiatric", "psychoemotional", "disorder" or "illness" are provided. Detailed information is sometimes given after the study is finished, never before.

* The investigations considered are: Goldberg and Blackwell11, 1970; Hesbacher et al..21, 1975; Hesbacher et al.20, 1975; Johnstone and Goldberg24, 1976; Hesbacher et al.22, 1978; Marks et al.33, 1979; Goldberg et al.14,15, 1980; Goldberg ${ }^{9}$, 1982; Goldberg et al.16. 1982; Goldberg10, 1984; Skuse and Williams ${ }^{45}$, 1984; Hoeper et al.23, 1984; Kessler et al. ${ }^{26}$, 1985; Bellantuono et al.4, 1985; Mari et al.32, 1986. 
- the Doctor's Scale is filled in after each consultation with the patients being studied; it is not always clear whether doctors are to score the presence and intensity of psychiatric disorder according to what they observe during that particular consultation or also based on their previous contacts with the patient.

- after the completion of the scoring phase, the results of the Doctor's Scale are compared to another assessment of psychiatric morbidity to which the same patients had been subjected minutes before (sometimes after) the scoring consultations. This assessment may be made by a clinical psychiatrist - by means of a standardized interview schedule or otherwise - or by a self-report symptom scale like the General Health Questionnaire, each of them determining the criteria for psychiatric caseness. The comparison of the doctors assessments with this criteria is expressed by indices of identification, bias and accuracy or agreement, which are clearly explained by Goldberg and Huxley ${ }^{12}$ (1980).

\section{A) Doctor's Awareness}

Epidemiologists tend to be very cautions when analysing the conditions under which data have been collected. As Lilienfeld and Lilienfeld $^{29}$ (1980) say:

"Another bias that may distort the findings from studies develops from the interviewer's awareness of the identity of cases and controls."

The same sort of care concerning awareness of observers is also found in other areas of scientific research, like Clinical Pharmacology, where double and triple-blind procedures are needed to avoid the observers' rating according to their previous knowledge of the groups of drugs being used. However peculiar it may look, to avoid this kind of bias proves to be important, particularly in those situations where the difference between two groups under observation is very small, and when the topic being investigated is influenced by a diversity of factors.

So is the case of Psychiatry, where factors other than the conditions of the diagnosed may exert a significant effect on diagnoses, mainly of those psychiatric disorders without any physically measurable sign. Studies carried out in the late fifties tried to show the influence of suggestion on psychiatric diagnosis. Temerlin $^{46}$ (1968) trained an actor to portray a complete mentally healthy person, and audiorecorded him being subjected to a diagnostic interview. The tapes were sent to departments of Psychiatry of teaching hospitals, where junior and senior staff were asked to give a psychiatric diagnosis, if there was any, and explain the reasons of their judgements. Before listening to the interview, three matched groups of psychiatrists were given different messages: the first group was told that ".. the patient on the tape is a very interesting man because he looks neurotic, but actually is quite psychotic."; the second group was given no message, and the third received a reversed suggestion, i.e., the patient being observed was an example of mental health. The results were remarkable, and showed that $60 \%$ of the first group of psychiatrists diagnosed psychosis, none of the third group made any diagnoses, and almost half the group where no suggestion was made said the patient was neurotic, but not psychotic. Caetano ${ }^{5}$ (1973), by means of the same design, but this time employing a "normal" actor and a psychiatric in patient in videorecorded diagnostic interviews, obtained identical results.

The first study (Temerlin ${ }^{46}, 1968$ ) concludes that:

"The demonstrated susceptibility of psychiatric diagnoses to distortion through suggestion could be determined in part by the nature of the concept of mental illness itself..... and since the norms of society and Psychiatry are vague, vary with culture and social class and usually are not explicit, diagnosis as labelling has to vary with the personal values and perceptual consistencies of the individual diagnostician."

Both authors emphasize the ambiguity of the concept of mental illness, and strongly "suggest" that further research is needed in this area. It is interesting to observe that only psychiatrists participated in these studies. There are no similar investigations with nonpsychiatrists, whose distortion on labelling mental illness may be even greater.

When primary care physicians score the presence and intensity of psychiatric disorder in their patients, some distortion is expected to occur. First, even if little, the routine of a health centre or a general practitioner's office is altered by the simple presence of any member of a research team; a doctor may have a wish to be involved in research, or may find it important though boring, so that 
he will act according to the new stimulus of the research team. Second, one of the researchers is often a psychiatrist himself, and it is well documented that the relationship between GPs and psychiatrists is not a very simple one, its roots being found in the medical school years, if not before (Krakowski ${ }^{27}$, 1973). An example of the influence of these stimuli on the behaviour of doctors can be seen in the work of Bellantuono et $\mathrm{al}^{4}$ (1985), who studied the rates of psychiatric disorder detected by one Italian general practitioner. They divided the doctor's scores into two groups: in the first, with 90 patients, the scores were made in periods in which the research psychiatrist was also interviewing patients; in the second group, 63 patients were scored in the absence of the psychiatrist. The results showed lower indices of identification of mental disorder in the second group, leading the authors to declare that:

“...the presence of a psychiatrist conducting a two-stage screening survey in the practice had a profound effect: her (the doctor's) threshold (for the presence of psychiatric disorder) was substantially lowered in the presence of the psychiatrist."

So far this is the only study conducted to investigate this sort of bias effect in the setting of primary care.

Perhaps a more constant - although subtle - influence on the way doctors assess the presence and intensity of psychiatric disorders is the assessing instrument itself, the Doctor's Scale. Even when there are no psychiatrists and no research assistants sitting in the waiting-room, there will always be a rating scale, be it a 5-point scale or any other; it functions as a "psycho" reminder, constantly suggesting to the possibility that, for each patient, there may be a psychiatric disorder (whatever the concept of that may be), and that it must fit one of the alternatives presented in the scale. Since in these scales there is no item expressing "I don't know", they have to fill in the scale as though they had performed some kind of psychiatric evaluation, which usually is not part of their routine evaluation of patients.

This last aspect must be emphasized. A researcher interested in the ability of urologists to describe lesions in the retina will certainly provide an ophthalmoscope, an instrument without which the examination of the retina is very limited. On the other hand, if the purpose of the investigation is to observe how many times urologists look for retinal abnormalities, then to offer an ophthalmoscope will strongly influence the routine procedures, possibly resulting in a higher rate of retinal observations. The same happens with the Doctor's Scales: their simple presence, by increasing the awareness of the doctors, alters the phenomena they propose to measure.

As in any other scientific enquiry, it is fundamental to know what question is being asked in order to avoid misinterpretation of the results obtained through this or that methodology. Is the question being asked "What is the rate of mental diagnoses made by primary care physicians?" or "Are doctors' rates of mental diagnoses above/the same as/ below those of psychiatrists?". An ideal solution to this conflict would be a longitudinal design where the psychiatric "gold standard" is applied at month 1, preferably accompanying any non-psychiatric research being done in primary care; at month 12 , or 24 , doctors' annotations in case-records of the patients are searched for a) mental diagnoses, formal and non-formal; b) phychotropic drug treatments; c) psychotherapy treatment and d) referral to mental health services and professionals; if any of these items is positive, detection is considered to have taken place. It may be arguable that doctors' detection of mental disorders in being under-reported by the use of this methodology, but its results are probably closer to the clinical picture of detection, and, in any case, the so-called Doctor's Scale has not yet proved to be any better, a subject that leads on to the next section.

\section{B) Accuracy of Instruments}

Although it would be ideal to apprehend the "truth" of the phenomena without interference of any sort, it is naive to expect such purity, particularly in psychiatric epidemiology where, to avoid vagueness, clear-aspossible methodological criteria have to be established. An ophthalmoscope - an instrument that can not be said to be sophisticated when compared to other optic devices - undoubtedly helps the observation of the ocular fundus. Such success is not achieved by the Doctor's Scales, particularly its 5, 6, 7 or 8-point versions, that more resemble a kaleidoscope, and are extensively to measure doctors' detection of mental illness, regardless of whether or not they have been previously submitted to proper validity and reliability tests. 
The first epidemiological studies done in primary care settings used to rely on retrospective information given by doctors' diagnoses of psychiatric disorders mainly under the World Health Organization International Classification of Diseases, following the same lines as investigators concerned in the morbidity of such other systems as the respiratory or digestive ones. A typical example is the survey conducted by Locke and Gardner ${ }^{30}$ (1969) in Monroe County in 1964; 58 primary care doctors reported to the authors all patients attended during a 1 -month period, and 14,117 case records were carefully examined for mental diagnoses. No definition of mental illness was given to the doctors, as the authors say:

"We did not ask the physicians to probe for psychiatric conditions, but to carry on their medical pratice in the usual way. Because of the nature of the study, emotional and mental illnesses were explained without specific criteria. We did not attempt to corroborate the diagnoses."

Whether the authors came across the work of Kessel before or after their field work is difficult to determine. The fact is that, in a study in a London general practice conducted in 56-57, Kessel ${ }^{25}$ (1960), working retrospectively with patients' record cards, found that there were many situations where psychiatric symptoms, although present in the doctors' notes, did not appear as formal diagnoses; then, after detailed discussion with the doctors involved in the study, a criterion was established, through which the doctors reviewed the record cards and re-assessed the same patients. The criterion is shown in Table 1.

Patients thus selected were regarded as belonging to the conspicuous psychiatric morbidity group, a term that is widely used in the recent studies. Kesse ${ }^{25}$ found that, with the new criteria, the prevalence of psychiatric

TABLE 1

Kessel's criteria*

(1) Some patients pointed the way explicitly by complaining of being anxious, depressed or fearful, irritable, nervous or unable to cope with life's routine.

(2) Some patients presented somatic symptoms which could not adequately be explained by physical illness, e.g. some cases of insomnia palpitations and menstrual disturbances.

(3) Some patients' psychological reactions to indisputable physical illness were in some ways abnormal.

* Kessel25 (1960).

morbidity was almost double, and when discussing these results, his opinion is that:

"The need for more precise criteria of psychiatric morbidity is shown by the absurdly different estimates which might have been derived from the present investigation. This is clearly a ridiculous state of affairs. ."

A few years later, Shepherd and colleagues conducted a larger morbidity survey in 46 London general practices, and the criteria used to define doctors' assessments divided psychiatric disorders into Formal Psychiatric Illness and Psychiatric-Associated Conditions, as can be seen from Table 2 (Shepherd et $\mathrm{al}^{44}$, 1966). The general practitioners taking part in the study were invited to meetings where the purpose was to instruct them in the survey technique and in the system of classification of mental disorders they were going to use.

TABLE 2

Shepherd's criteria*

\section{Formal Psychiatric Illness}

1. Psychosis

2. Mental Subnormality

3. Dementia

4. Neurosis

5. Personality Disorder

\section{Psychiatric-Associated Conditions}

6. Physical Illnesses

7. Physical Symptoms

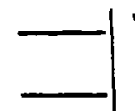

where psychological mechanisms have been important in the development of the condition

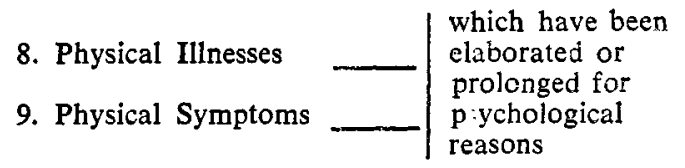

10. Other psychological or social problems

* Shepherd et al44 (1966).

Since Shepherd's study, many changes have occurred in the definition of a criterion for doctors' assessment of mental illness. Amazingly, the most remarkable modification came in a single publication, entitled "Psychiatric Illness in General Practice. A Detailed Study Using a New Method of Identification" (Goldberg and Blackwell1", 1970). The "new 
method" is related to the General Health Questionnaire - (GHQ), a self-administered screening instrument devised to focus on minor psychiatric disturbances. But the "new" that is the concern of this section is another one, also presented in the same article, although in a way that is hardly noticeable: it is the use of a simple, small, unsophisticated scale utilized by the doctor when evaluating the presence and intensity of psychiatric disorder. The "X-point scale", as it will be called from now on (it can be a 5, 6, 7, $8, \ldots$-pont scale), consists of statements that range from $[0]=$ no psychiatric disorder, to $[X]=$ severe psychiatric disorder. An example of a 5-point scale is given in Table 3.

TABLE 3

Goldberg's criteria*

$(0)=$ no psychiatric disturbance detected

(1) $=$ mild subclinical emotional disturbance

(2) = clinically significant psychiatric illness - mild

(3) $=$ psychiatric illness - moderate

(4) $=$ psychiatric illness - marked

* Goldberg and Blackwell" (1970).

Noteworthy is the number of terms like "subclinical", "mild", "disturbance", "emotional", and the fact that no detailed explanation of them is shared with the doctors. These X-point scales are the ones that have been used in epidemiologic research since the late sixties, with few exceptions (Hesbacher et $\left.\mathrm{al}^{20}, 1975\right)$. And nowhere is any explanation to be found as to why they were the instruments chosen to measure doctors' detection of mental illness, although they have been employed in many different circumstances.

When trying to discover the origin of these scales, one always meets obscurity and is referred back to an earlier paper; it seems that no author attributes much importance to it. But one traceable origin is located in Philadelphia, where Rickels and colleagues, working on psychiatric drug research, expressed their interest in the use of simple but sensitive measures of neurotic symptomatology that could be easily understood and familiar to scoring doctors. One of them is the Physician's Questionnaire (Rickels and Howard ${ }^{40}$, 1970), containing 10 items related to somatic and emotional symptoms, each item to be scored on a 7-point scale. Anxiety, for exam- ple, could be scored from " $[0]=$ not present" to " $[6]=$ extremely severe", and so on with depression, somatization, insomnia, etc. The instrument was shown to discriminate drugplacebo differences well. In another article, Rickels et $\mathrm{al}^{41}$ (1970), this time testing the reliability of an 8-point scale to assess global psychopathology, found very low indices of agreement both for inter and intra-individual scores. It is the authors interpretation that:

"In evaluating psychopathology,.. doctors. .are comparing the patient against a set of internal criteria, and furthermore are required to estimate global neurotic pathology, which is a somewhat diffuse concept...It is also true that in a number of our clinical drug studies where several doctors are involved, global ratings of psychopathology have been less sensitive in detecting drug- placebo differences than other criterion measures."

Both the studies described above involved only psychiatrists: residents, hospital staff, experienced clinicians, all were psychiatrists. The validity and reliability characteristics of X-point scales were never tested when used by non-psychiatric doctors, whose diffuseness in the conceptualization of neurotic pathology is probably greater than that of psychiatrists.

Notwithstanding, Rickles - now with Hesbacher and Goldberg - seems to have been persuaded by some undeclared advantages of the X-point scale, for it is the instrument adopted in his large survey undertaken in Pennsylvania in 1970 (Hesbacher et $\mathrm{al}^{21}$, 1975). The justification is:

"Since both patients and doctors are intended to present overall assessments of symptomatology the physician was asked to make a single estimate of psychopathology by indicating on a seven-point scale... the patients level of emotional impairment compared with other patients seen in the office."

It happened that, using their low-reliability, low-validity scale, doctors - now primary care physicians - scored 1,195 patients, and good indices of agreement between doctors' and patients' evaluation of mental illness were obtained, leading the authors to affirm:

". . the substantial agreement..lends support to the growing belief that family physicians have an important role to play 
in the detection and treatment of emotional illness."

This is only one small example of how far the conclusions based on the $\mathrm{X}$-point scales can go.

The reason for adopting such an instrument may derive from different sources that cannot be found explicity in accessible documentation, thus allowing speculation on some hypotheses. First, this scale is easy to fill in, only one of its short statements is to be selected; it is quickly administered, taking no more than a minute for each patient. These characteristics help the researcher a lot when he asks for doctors' collaboration on the study. Second, if any instrument will introduce some bias into observers' awareness, the $\mathrm{X}$-point scale is possibly the one with the smallest effect, for it causes very little alteration of the routine, and at the same time does not introduce "new" criteria of mental disorder. Third, being applied at the same time as the actual consultations with the patients, investigators can make use of cross-sectional study designs, instead of the time-consuming search of case records in the retrospective designs; furthermore, it enables the relatively rapid testing of experimental models of medical education by comparing, for example, the ability to detect mental illness in a group of doctors trained in a new curriculum and in a control group.

Better understanding of the features of these instruments is obviously needed. Experimental studies where doctors are invited to scoring sessions of in vivo consultations observed through one-sided mirrorred rooms, or video-taped interviews; intra and inter raters scores must be compared, and these also compared to psychiatric "gold standards" applied at the same time, with a view to determining sensitivity and specificity values; modifications must be made until, and if, acceptable results are obtained. Only then, may X-point scales or any other instrument whose purpose is to measure doctors detection of mental disorder, be confidently used.

\section{C) Conceptual Clash}

In order not to be trapped between diminishing observers' bias and increasing the accuracy of instruments, what is required at this point is a close inspection of the concepts involved in this area of epidemiological research, which is substantially diverse from others. When studying measles for example, both epidemiologists and physicians will share approximately similar concepts of the disease (its aetiology, clinical picture, treatment..), even though the criteria for caseness may be more restricted for the former, depending on the kind of study being done. The same cannot be said of the concept of minor psychiatric disorder, and, in fact, doctors and psychiatrists participating in epidemiologic research display different notions of what is a psychiatric case, leading thus to an inevitable conceptual clash, as will tentatively be shown.

\section{Psychiatrists'View}

In Primary Care settings, the instrument most broadly used to define what is a psychiatric case is the General Health Questionnaire - GHQ, described by Cooper and Morgan" (1973) as ". noteworthy for the care with which it has been designed and validated" and "...a distinct advance over most of the earlier screening tests." Constructed to identify non-psychotic psychiatric disorders, this self-report questionnaire takes 5-15 minutes to answer, and is the result of about 5 years of careful work. The author (Goldberg ${ }^{8}, 1972$ ) initially selected 140 items from various sources, such as previous instruments (Cornell Medical Index, Eysenck Personality Inventory, MMPI..), discussions with previously experienced psychiatrists and other works. The items were divided into four main areas: depression, anxiety, hypochondriasis and objectively observable behaviour. Later rearranged under 7 headings, the items were submitted to several studies in order to obtain measurements of their accuracy; further analysis was performed to select the most discriminant items, thus permitting the use of shorter forms containing $60,30,18$ and 12 items. The best cut-off points were found for different settings and for males and females. Some of these items, according to one of the four groups to which they were first allocated, are:

Depression - Have you been losing confidence in yourself? Have you been feeling reasonably happy, all things considered?

Anxiety - Have you been feeling nervous and strung up all the time? Have you found at times that you couldn't do anything because your nerves were too bad?

Hipochondriasis - Have you been getting a feeling of tightness or pressure in your head? Have you been able to concentrate on whatever you're doing? 
Observable Behaviour - Have you been feeling on the whole that you were doing things well? Have you been able to feel warmth and affection for those near you?

As can be seen, the items or questions that are actually made to the patients, are not complicated, and not greatly different from the questions a doctor is able to ask.

\section{Doctors'Gaze}

Doctors are introduced to the concepts of disease and illness even before deciding to do Medicine, for it has been shown that laymen also share the same beliefs of what a disease is (Campbell et $\mathrm{al}^{6}$, 1979). Nevertheless, it is during the scientifically oriented years of medical school that this learning process is consummated. The pre-clinical years are dedicated to the study of the normal body (Physiology, Anatomy), then to the abnormal functioning and structures; all tied together by studying how the altered organs express themselves through symptoms and signs, which are to be apprehended in careful anamneses, physical examinations, and laboratory tests. The positive findings lead to a diagnosis (usually single), an element without which no treatment can be performed. This is what medical students are stimulated to study, these are the subjects that occupy most of the curriculum time, that count in terms of importance, of passing examinations, of being a "good doctor" (Atkinson", 1984). When medical students begin their clinical years, they have already assimilated this information, they approach their patients with the only method they know, "Where does it hurt?", "Please say ninety-nine..", "These are the blood tests I'd like you to make.."

Non-organic mental illness is not part of the universe introduced to medical students, who usually find it interesting but far from being a priority in their activities. Courses of Psychiatry and Medical Psychology - with few exceptions - tend to proudly present typical psychiatric syndromes like paranoid schizophrenia, maniac psychosis, situations that a future primary care physician (or a specialist) will seldom face in their practices. Moreover, the case presentation and discussion in these courses is often carried out on the same basis as in other scientific branches of Medicine, suggesting that, if an organic aetiology of the mental disorder has not yet been found, it will eventually be, and this is the method to be followed. Psychiatry courses that emphasize the human and psycho-social aspects of disease are known to favourably influence students' attitudes towards psychiatry and mental illness (Meltzer and Grigorian ${ }^{34}$, 1972; Wilkinson et $\mathrm{a} 1^{49}, 1983$ ), but only for a short period after the completion of the courses, and mainly in the case of those students who had previously demonstrated interest in the humanistic and psycho-social approach to Medicine (Rezler ${ }^{39}$, 1974).

If what is non-objective, non-scientific, nonorganic, does not go through a formal process of labelling, it by no means escapes notice. Although it is not to be found in textbooks, every schoolboy knows the meaning of terms like "crock", "rubbish" or "duff referrals".

Students and doctors thus express their opinion as regards those whom they prefer to treat, and it has been shown that some negative stereotypes are created to label alcoholics, drug addicts, obese patients, "hipochondriacs", etc. (Najman and Arnold, 1984; Harris et $\mathrm{al}^{18}$, 1985). It seems that medical training reinforces some of the beliefs held by society at large $\left(\right.$ Mechanic $\left.^{34}, 1962\right)$.

There is finally a last factor to be considered here, a cognitive feature that is often denied in studies concerning doctors' concepts of psycho-emotional disorders. The high rates of suicide, alcoholism, drug addiction and depression have been extensively described amongst the medical profession (Balint ${ }^{2}, 1966$; Murray $^{36}$, 1983). During the experience of medical school, idealistic youths are turned into detached, emotionally cold, cynical professionals, who permit themselves fewer leisure hours, less family and social life (Becker and $\mathrm{Geer}^{3}$, 1958; Whittemore et $\left.\mathrm{al}^{47}, 1985\right)$. Helfer $^{19}$ (1970), observing the behaviour differences between freshman and fifth-year medical students, bitterly described the latter as "robots", when interviewing an actor-patient. Hectic desires to fight death and combat disease make a faustian alliance with scientific and technological promises of a final victory. "The doctors first consulting room is the autopsy arena, their first patient is a corpse..." (Lewin $\left.{ }^{28}, 1946\right)$, they are not allowed to feel sick when they face a cadaver, the body is to be seen as an object of study, no fainting in the surgery room, no room to cry for a dying patient, says the unofficial medical curriculum. And since a minimum of empathy and identification with suffering is essential for the understanding of other people's emotional complaints, it is no to be expected that doctors should be very good at 
it. The influence of this emotional factor in the apprehension of concepts of mental illness by doctors has still to be properly examined.

Given such a large number of variables, the wide range of diagnostic fashions encountered in different primary care practices is hardly surprising. The doctors gaze of mental illness sees a universe that is different from that of psychiatrists. To compare their evaluation of patients is not to compare "like with like", one of the very basic principles in Epidemiology.

\section{CONCLUSION}

From what has been discussed above, epidemiologic investigation into primary care physicians' ability to detect mental disorders needs certainly to improve its quality. Better project designs can be implemented; only instruments that have been tested and accepted must be used. But all this proves to be pontless until very clear, usable concepts of minor mental illness are shared both by doctors and research psychiatrists. Some measures are already being taken with a view to achieving this conceptual unity, but they usually consider only a oneway flow of knowledge, from psychiatrists to non-psychiatrists. Von Senden (whose quotation appears at the beginning of this review) and his ex-blind patients seem to have agreed that the possession of vision makes life better, and the flow of useful information would naturally be from those who have always had the ability to see to those ho have not. This is not necessarily the case with psychiatrists and primary care physicians. If psychiatrists have fluency in their speciality, they still know very little about minor psychiatric disorder, their course and their treatment, and they have not yet shown that their vision of these disorders makes life any better. For the time being, it is still just a supposition that the disorders which psychiatrists are so concerned with are a problem to the primary care physician, who may, on the other hand, consider "troublesome" or "psychiatric" completely different sorts of behaviour.

A suggestion worth making, with so much light still to come from different sources, is that it is time for psychiatrists to sit down with primary care doctors, within the latters' setting, from within which both will try to decide which pair of glasses is best suited to the desired purposes, a process that will obviously take time. This is a better way of obtaining, if not scientific "truths", at least more practical, rational and satisfactory ways of offering medical care.

\section{ACKNOWLEDGEMENTS}

To Dr. Paul Williams and Professor Michael Shepherd from the General Practice Research Unit, Institute of Psychiatry, for their comments on earlier drafts of this paper; and particular thanks to Dr. Jair J. Mari of the "Escola Paulista de Medicina" (S. Paulo, Brazil) for his suggestions and constant encouragement in all phases of this study.

IACOPONI, E. Metodologias utilizadas para detectar distúrbios emocionais em clínicas de assistência primária à saúde. Revisão de literatura. Rev. Saúde públ., S. Paulo, 22:46-66, 1988.

RESUMO: Na área de epidemiologia psiquiátrica vêm sendo realizados, nos últimos vinte anos, estudos que têm como finalidade medir a habilidade que clínicos gerais possuem em detectar distúrbios emocionais nos pacientes que procuram atendimento na rede básica de saúde. A metodologia utilizada nesses estudos é o tema central da atual revisão, que contém a) viés do entrevistador; b) acuidade dos instrumentos; e c) conceitos médicos e psicológicos envolvidos na definição de distúrbio psiquiátrico menor. São também apresentadas sugestões para mudanças de metodologia.

UNITERMOS: Métodos epidemiológicos. Distúrbios mentais, diagnóstico. Assistência primária à saúde. Exames de massa, métodos. 


\section{REFERENCES}

1. ATKINSON, P. Training for certainty. Soc Sci. Med., 19:949-56, 1984.

2. BALINT, M.; BALINT, E.; GOSLING, R.; HILDEBRAND, P. A study of doctors. London, Tavistock Publications, 1966.

3. BECKER, H. S. \& GEER, B. The fate of idealism in medical school. Amer. saciol. Rev., 23:50-6, 1958.

4. BELLANTUONO, C.; FIORIO, R.; WILLIAMS, P.; CORTINA, P. Psychiatric morbidity in an Italian general practice, 1985. Unpublished report*.

5. CAETANO, D. F. Labelling theory and the presumption of mental illness: an experimental design. J. Hlth soc. Behav., 15:253-60, 1973.

6. CAMPBELL, E. J. M.; SCADDING, J. G.; ROBERTS, R. S. The concept of disease. Brit. med. J., 2:757-62, 1979.

7. COOPER, B. \& MORGAN, H. G. Epidemiological psychiatry. Boston, Charles C. Thomas, 1973.

8. GOLDBERG, D. The detection of psychiatric illness by questionaire. London, Oxford University Press, 1972 (Institute of Psychiatry, Maudsley Monographs n. 21).

9. GOLDBERG, D. The recognition of psychological illness by general practitioners. In: Clare, A. W. \& Lader, M., ed. Psychiatry and general practice. London, Academic Press, 1982.

10. GOLDBERG, D. The recognition of psychiatric illness by non-psychiatrists. Aust N.Z.J. Psychiatry, 18:128-33, 1984.

11. GOLDBERG, D. \& BLACKWELL, B. Psychiatric illness in general practice: a detailed study using a new method of case identification. Brit. med. J., 2:439-43, 1970.

12. GOLDBERG, D. \& HUXLEY, P. Mental illness in the community. London, Tavistock Publications, 1980.

13. GOLDBERG, D. \& KESSEL, N. Psychiatric research in general practice. In: Sainsbury, P. \& Kreitman, N., ed. Methods of psychiatric research. London, Oxford University Press, 1975.

14. GOLDBERG, D.; STEELE, J. J.; SMITH, C. Teaching psychiatric interview techniques to family doctors. Acta psychiatr. scand, 62 (Supp.1 285) :41-7, 1980.

15. GOLDBERG, D.; STEELE, J. J.; SMITH, C.; SPIVEY, L. Training family doctors to recognize psychiatric illness with increasing accuracy. Lancet, 2.:521-3, 1980.

16. GOLDBERG, D.; STEELE, J. J.; JOHNSON, A.; SMITH, C. Ability of primary care physicians to make accurate ratings of psychiatric symptoms. Arch. gen. Psychiatry, 39: 829-33, 1982.

Available with the author of this article.
17. HANKIN, J. \& OKTAY, J. S. Mental disorder and primary medical care; an analytical review of the literature. Rockville, National Institute of Mental Health, 1979. (Séries D, n. 5).

18. HARRIS, I. B.; RICH, E. C.; CROWSON, T. W. Attitudes of internal medicine residents and staff physicians towards various patient characteristics. J. med. Educ., 60:192-5, 1985.

19. HELFER, R. E. An objective comparison of the pediatric interviewing skills of freshman and senior medical students. Pediatrics, 45: 623-7, 1970.

20. HESBACHER, P.; SCHEIN, L.; LEOPOLD, R. L. Psychiatric illness detection: a comparison of osteopaths amd M. D.s in private family practice. Soc. Sci. Med., 9:461-8, 1975.

21. HESBACHER, P.; RICKELS, K.; GOLDBERG, D. Social factors and neurotic symptoms in family practice. Amer. J. publ. Hlth, 65: $148-55,1975$.

22. HESBACHER, P.; RICKELS, K.; DOWNING, R. W.; STEPANSKY, P. Assessment of psychiatric illness severity by family physicians. Soc. Sci. Med., 12:45-7, 1978.

23. HOEPER, E. W.; KESSLER, L. G.; NYCZ, G. R.; BURKE Jr., J. D.; PIERCE, W. E. The usefulness of screening for mental illness. Lancet, 1:33-5, 1984.

24. JOHNSTONE, A. \& GOLDBERG, D. Psychiatric screening in general practice. Lancet, 1: $605-8,1976$.

25. KESSEL, W. I. N. Psychiatric morbidity in a London general practice. Brit. J. prev. soc. Med., 14:16-22, 1960

26. KESSLER, L. G.; AMICK III, B. C.; THOMP. SON, J, Factors influencing the diagnosis of mental disorders among primary care patients. Med. Care, 23:50-62, 1985.

27. KRAKOWSKY, A. J. Doctor-doctor relationship III: a study of feelings influencing the vocation and its tasks. Psychosomatics, 14: 156-61, 1973.

28. LEWIN, B. D. Counter-transference in the technique of medical practice. Psychosom. Med., 8:195-9, 1946.

29. LILIENFELD, A. M. \& LILIENFELD, D. E. Foundations of epidemiology. New York, Oxford University Press, 1980.

30. LOCKE, B. Z. \& GARDNER, E. A. Psychiatric disorders among the patients of general practitioners and internists. Publ. Hlth Rep., 84: 167-73, 1969.

31. MACMAHON, B. \& PUGH, T. F. Epidemiology: principles and methods. Boston, Little Brown \& Co., 1970.

32. MARI, J. J.; IACOPONI, E.; WILLLAMS, P.; SIMOES, O.; SILVA, L. B. T. Detection of psychiatric morbidity in the primary medical care setting in Brazil. Rev. Saúde públ., S. Paulo, 21:501-7, 1987. 
33. MARKS, J. N.; GOLDBERG, D.; HILLIER, V. F. Determinants of the ability of general practitioners to detect psychiatric illness. Psychol. Med., 9:337-53, 1979.

34. MECHANIC, D. Some factors in identifying and defining mental illness. Ment. Hyg., 46: 66-74, 1962 .

35. MELTZER, M. \& GRIGORIAN, H. Effect of psychiatric education on attitudes of medical students to mental illness. Psychiatry, 35: 195-204, 1972.

36. MURRAY, R. M. The mentally ill doctor: some causes and consequences. Practitioner, 227:65-75, 1983.

37. NAJMAN, J. M. \& ARNOLD, L. An initial explanatory model of medical students' preferences for patients types. Med. Educ., 18: 249-54, 1984.

38. REGIER, D. A.; GOLDBERG, I. D.; TAUBE, C. A. The De Facto mental health services system. Arch. gen. Psychiatry, 35:685-93, 1978.

39. REZLER, A. Attitude changes during medical school: a review of the literature. J. med. Educ., 49:1023-30, 1974.

40. RICKELS, K. \& HOWARD, K. The physician questionnaire: a useful tool in psychiatric drug research. Psychopharmacology, 17: $338-44,1970$.

41. RICKELS, K.; HOWARD, K.; LIPMAN, R. S.; COVI, L.; PARK, L.; UHLENHUTH, E. H. Differential reliability in rating psychopathology and global improvement. $J$. clin. Psychol., 26:320-3, 1970.

42. SENDEN, M. Space and sight: the perception of space and shape in congenitally blind patients before and after operation. London, Methuen, 1960.
43. SHEPHERD, M. \& COOPER, B. Epidemiology and mental disorder: a review. J. Neurol. Neurosurg. Psychiatry, 27:277-90, 1964.

44. SHEPHERD, M.; COOPER, B.; BROWN, A. C.; KALTON, G. W. Psychiatric illness in general practice. London, Oxford University Press, 1966.

45. SKUSE, D. \& WILLIAMS, P. Screening for psychiatric disorder in general practice. Psychol. Med., 14:365-77, 1984.

46. TEMERLIN, M. K. Suggestion effects in psychiatric diagnosis. J. ment. and nerv. Dis., 147:349-53, 1968.

47. WHITTEMORE, P. B.; BURSTEIN, A. G.; LOUCKS, S.; SCHOENFELD, L. S. A longitudinal study of personality changes in medical students. $J$. med. Educ., 60:404-5, 1985.

48. WILKINSON, G. Mental health practices in primary care setting: an annotated bibliography, 1977-1985. London, Tavistock Publications, 1985.

49. WILKINSON, B.; TOONE, B. K.; GREER, S. Medical students' attitudes to psychiatry at the end of the clinical curriculum. Psychol. Med., 13:655-8, 1983.

50. WORLD HEALTH ORGANIZATION. Regional Office for Europe. Psychiatry and primary medical care. Copenhagen, 1973.

51. WORLD HEALTH ORGANIZATION. Primary health care; report of the Alma-Ata conference. Geneva, 1978.

Received for publication: 22-6-1987 Accepted for publication: 14-10-1987 